\title{
A survey of reasons for continuing warfarin therapy in the era of direct oral anticoagulants in Japanese patients with atrial fibrillation: the SELECT study
}

This article was published in the following Dove Press journal:

Patient Preference and Adherence

\section{Takanori Ikeda' \\ Masahiro Yasaka ${ }^{2}$ \\ Makoto $\mathrm{Kida}^{3}$ \\ Miki Imura ${ }^{4}$}

'Department of Cardiovascular Medicine, Toho University Faculty of Medicine, Tokyo, ${ }^{2}$ Department of Cerebrovascular Medicine and Neurology, National Hospital Organization, Kyushu Medical Center, Fukuoka, ${ }^{3}$ Medical \& Development, Bristol-Myers Squibb KK, Tokyo, ${ }^{4}$ PIH Medical Affairs, Pfizer Japan Inc, Tokyo, Japan
Correspondence: Miki Imura PIH Medical Affairs, Pfizer Japan Inc, Shinjuku Bunka Quint Building, 3-22-7, Yoyogi, Shibuya-ku, Tokyo I5I-8589, Japan

Tel +818050013070

Fax +8I 353099198

Email miki.imura@pfizer.com
Purpose: Although warfarin has historically been the standard of care for preventing ischemic stroke in patients with nonvalvular atrial fibrillation (NVAF), the use of direct oral anticoagulants (DOACs) is rapidly increasing. In this study, we examined the demographic and clinical characteristics of patients continuing warfarin therapy and investigated reasons for warfarin continuation.

Patients and methods: Each study site consecutively registered 10 patients with NVAF who had been taking warfarin for at least 12 months. Demographic and clinical characteristics and international normalized ratio (INR) values were collected from medical records. Physicians responded to questionnaires exploring reasons for continuing warfarin therapy.

Results: Overall, 313 patients treated with warfarin were registered at 33 sites. Mean \pm SD age was $76.4 \pm 9.6$ years; $62.9 \%$ of patients were male. The proportion of patients with INR values in the therapeutic range was $74.6 \%$ and $48.8 \%$ among patients aged $\geq 70$ years and $<70$ years, respectively. Over half of the patients $(51.4 \%)$ had been advised to switch from warfarin to DOACs; the primary physician-reported reason for this recommendation was superior safety and effectiveness. However, patients reported continuing warfarin because of the high price of DOACs (47.2\%) and long-term positive experiences with warfarin $(31.7 \%)$. The remaining $48.6 \%$ of patients with NVAF had never been counseled by their physicians about DOACs as an alternative to warfarin. For $76 \%$ of these patients, physicians favored warfarin for medical reasons, such as impaired renal function and controlled INR, but in the remaining patients, medical reasons for continuing warfarin were lacking.

Conclusion: Approximately half of the patients in this study were informed of warfarin alternatives primarily for improved efficacy and safety, but elected not to change regimens because of the high price of DOACs and long-term positive experiences with warfarin. In the remaining half, physician preference or specific patient characteristics prevented a change in therapy.

Keywords: anticoagulant, physician preference, nonvalvular atrial fibrillation, patient satisfaction

\section{Plain language summary}

Although warfarin has historically been the standard of care for preventing ischemic stroke in patients with nonvalvular atrial fibrillation, the use of direct oral anticoagulants (DOACs) is rapidly increasing. We examined the demographic and clinical characteristics of patients continuing warfarin therapy and investigated reasons for warfarin continuation in the era of DOACs. More than half of the patients $(51.4 \%)$ had been advised to switch from warfarin to DOACs; the primary physician-reported reason was "better safety and effectiveness profile of DOACs compared with warfarin". However, patients reported continuing warfarin because of the high price of DOACs (47.2\%) and long-term positive experiences with warfarin $(31.7 \%)$. The remaining $48.6 \%$ of patients had never been counseled by their physicians about DOACs 
as an alternative to warfarin. For $76 \%$ of these patients, physicians favored warfarin for medical reasons (eg, impaired renal function and controlled international normalized ratio), but in the remaining patients, medical reasons for continuing warfarin were lacking.

\section{Introduction}

Atrial fibrillation (AF) is a common arrhythmia in elderly populations and a major risk factor for cardioembolic stroke, which can lead to serious disability and diminished quality of life. ${ }^{1-4}$ The incidence of AF is on the rise, and major cardiovascular risk factors, including age, male gender, hypertension, heart failure, and obesity, are known to increase the risk of developing $\mathrm{AF}^{5-7}$ Current $\mathrm{AF}$ treatment guidelines recommend the use of an oral anticoagulant (OAC) for prevention of cardioembolic stroke in patients with AF when additional risk factors are present. ${ }^{8,9}$ Historically, warfarin has been the OAC of choice in AF. However, patients taking warfarin must monitor their anticoagulation status with regular measurements of international normalized ratio (INR) values. Even with routine testing, therapeutic INR values are difficult to maintain and are prone to fluctuations outside of the relatively narrow therapeutic range. Deviations in INR values may lead to serious outcomes including thrombosis and bleeding. In addition to regular monitoring, patients on warfarin must carefully regulate their diet and concomitant medications, avoiding antiplatelet drugs, nonsteroidal anti-inflammatory drugs, and other medications that may increase bleeding or interact with warfarin, thus imposing an additional burden on patients. Furthermore, it has been suggested that warfarin therapy may be associated with increased arterial stiffness. ${ }^{10}$

Recently, direct oral anticoagulants (DOACs), also known as non-vitamin $\mathrm{K}$ antagonist OACs, have been introduced for stroke prevention in patients with AF. DOACs - dabigatran, rivaroxaban, apixaban, and edoxaban - have shown superior or noninferior safety and efficacy compared to warfarin in large randomized controlled trials ${ }^{11-13}$ and in real-world settings. ${ }^{14-20}$ Although many patients with nonvalvular AF (NVAF) have switched to DOAC therapy, a significant proportion of patients are still treated with warfarin. The AGAIN study ${ }^{38}$ was a prospective observational study conducted in Japanese patients with NVAF that investigated patient-reported satisfaction with apixaban after switching from warfarin (UMIN000018970). In this study, most physicians switched patients to apixaban in compliance with treatment guidelines, ${ }^{21}$ but many patients remained on warfarin for reasons unsubstantiated by scientific evidence, including higher prices of DOACs compared to warfarin, lack of pressing reasons to switch (INR stably controlled within the therapeutic range), and fear of the potential risks of bleeding or ischemic events during the transition, either due to an overlap or a gap between warfarin and DOAC coverage. A further analysis of these reasons, as well as the characteristics of patients who remained on warfarin, was not explored in the study.

Therefore, the aim of this study was to investigate the reasons for continuing warfarin rather than switching to DOACs. Additionally, we examined the demographic and clinical characteristics of patients who continued warfarin treatment compared with patients who switched to DOACs.

\section{Methods}

\section{Statement of ethics}

This multicenter, retrospective study was conducted in accordance with the principles of the Declaration of Helsinki and was approved by each hospital's ethics committee or by a central ethics committee (Supplementary materials, Table S1). The study is registered with UMIN-CTR, a clinical trial registry in Japan (study ID: UMIN000024531).

\section{Study design}

This study consisted of retrospective data collection of the patient's medical record and a questionnaire on the physician's perception on warfarin use in general. Physicians and investigators made a contract involving provisions and usage of the data for this study. Patient-level data, including patients' clinical and demographic characteristics and INR values, were retrospectively collected from medical records. To obtain the reasons why patients chose to continue the use of warfarin though they were advised to switch to DOAC, physicians, not patients, completed a questionnaire retrospectively based on a medical chart of each patient. Data including evaluations of physicians' knowledge and beliefs of warfarin-based anticoagulant therapy and general treatment strategies for NVAF were also collected. All data provided from physicians were deidentified. In this study, as no primary data collection of patient data was conducted, written informed consent was not required for this study according to local regulations in Japan.

\section{Study sites}

In total, 33 sites (10 hospitals and 23 clinics) were randomly selected from the institutions participating in the AGAIN study. Of these 33 institutions, 28 specialized in cardiology. Ten or more patients were registered consecutively at each site.

\section{Study population}

Adult Japanese patients with NVAF who had been treated with warfarin for prevention of cardioembolic stroke and 
systemic embolism for at least 12 months before the index date (defined as the date of contract execution between Pfizer Japan and the study site) and who had never been treated with DOACs were eligible for the study. At each institution, the first 10 consecutive patients to meet enrollment criteria were selected retrospectively from the index date to eliminate selection bias. A total of 313 patients were ultimately enrolled in the study.

\section{Data collection}

Patient demographic and clinical characteristics were retrospectively collected from the medical record to construct a dataset for the 1-year period preceding each patient's most recent hospital visit. Each patient's physician received a questionnaire regarding the reasons for recommending or not recommending switching from warfarin to a DOAC (Figure 1, Q2 and Q4) and the reasons the patient declined to comply with this recommendation (Figure 1, Q3). Additionally, with the assistance of a contract research organization (Mebix Inc., Tokyo Japan), we sent a second questionnaire to the same group of physicians that addressed their general (non-patient-specific) strategies and beliefs regarding anticoagulant therapy with warfarin and DOACs (Supplementary materials, Figure S1).

\section{Statistical methods}

For continuous variables, the mean $\pm \mathrm{SD}$, median, minimum, and maximum were calculated. Proportions are presented as percentages. Differences in patient characteristics between

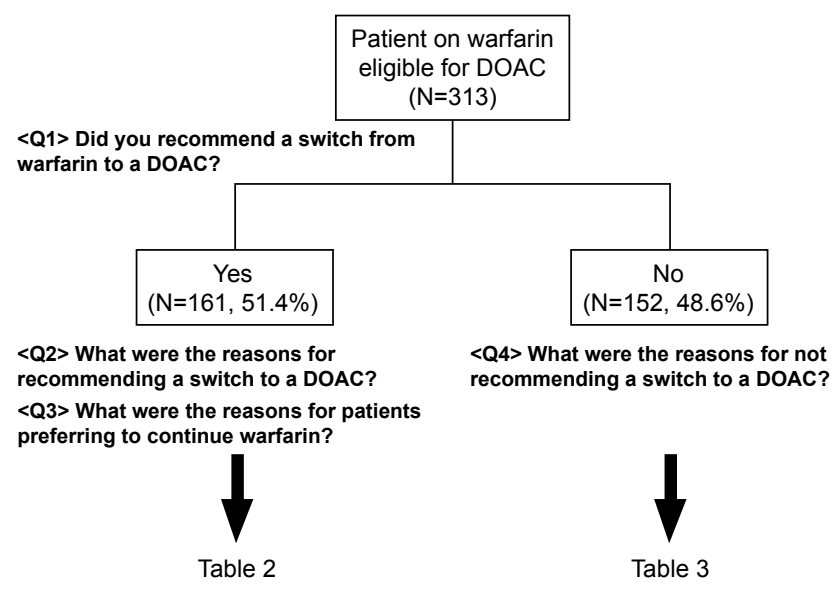

Figure I Flowchart of questions about physician recommendations to switch to DOACs or continue warfarin.

Notes: For each patient, physicians were asked Q I to distinguish between patients who had received a recommendation to switch to DOACs and those who had not. For the former, physicians were then asked Q2 and Q3 to identify the underlying reason for the recommendation and the reason that the patient did not comply with the recommendation. For the latter, physicians were asked Q4 to identify the reason for not recommending switching from warfarin to DOACs.

Abbreviation: DOAC, direct oral anticoagulant. patients treated with warfarin in the current study and those who switched from warfarin to apixaban in the AGAIN study were compared using the paired $t$-test or chi-square test. Statistical analyses were conducted using SAS version 9.4 software (SAS Institute Inc., Cary, NC, USA).

\section{Results}

\section{Patient characteristics}

In total, 313 patients who met inclusion criteria were registered at 33 institutions. Patient demographic and clinical characteristics were collected retrospectively. Thirty-eight physicians answered questions regarding patient-specific reasons for continuing warfarin therapy, as well as additional questions addressing their knowledge and beliefs about anticoagulant therapy with warfarin and DOACs.

Patient demographic and clinical characteristics are shown in Table 1. Mean \pm SD age was $76.4 \pm 9.6$ years $(73.5 \%$ of patients were $\geq 70$ years old); $62.9 \%$ of patients were male. Mean $\pm \mathrm{SD} \mathrm{CHADS}_{2}, \mathrm{CHA}_{2} \mathrm{DS}_{2}-\mathrm{VASc}$, and HASBLED scores were $2.3 \pm 1.2,4.1 \pm 1.8$, and 2.6 \pm 1.2 , respectively. Baseline INR values were within the recommended therapeutic range for $74.6 \%$ of patients aged $\geq 70$ years and $48.8 \%$ of patients aged $<70$ years.

The mean \pm SD annual number of INR measurements was $9.2 \pm 3.9$ in patients aged $\geq 70$ years and $8.2 \pm 3.6$ in those aged $<70$ years; $43.0 \%$ and $36.1 \%$ of patients had changed warfarin dosages during the 52 weeks before the index date among patients aged $\geq 70$ years and $<70$ years, respectively.

There was no significant difference in INR values between patients $<70$ years old and those $\geq 70$ years old (2.0 \pm 0.5 and $2.0 \pm 0.4$, respectively; $P=1.000)$ (Table 1$)$. Additionally, Figure 2 shows mean \pm SD INR values at times when warfarin doses were increased $(1.59 \pm 0.42$ in patients aged $\geq 70$ years and $1.82 \pm 0.43$ in patients aged $<70$ years) and those at times when doses were decreased (2.60 \pm 0.77 in patients aged $\geq 70$ years and $2.78 \pm 0.72$ in patients aged $<70$ years). The timing of dose changes was similar between the two groups.

\section{Reasons for switching to DOACs or continuing warfarin}

Figure 1 shows a flowchart of the questions presented to physicians regarding switching from warfarin to DOACs and patients' reasons for continuing warfarin despite physician recommendations. Approximately half of all patients (51.4\%) who continued warfarin treatment had been advised to switch from warfarin to a DOAC. The primary reason among physicians for recommending DOACs was "a better safety and effectiveness profile for DOACs compared with warfarin" 
Table I Patient demographic and clinical characteristics

\begin{tabular}{|c|c|c|c|c|}
\hline & Total $(\mathbf{N}=3 \mid 3)$ & $<70$ years old $(\mathrm{N}=83)$ & $\geq 70$ years old $(\mathrm{N}=230)$ & $P$-value ${ }^{a}$ \\
\hline Male gender & $197(62.9)$ & $65(78.3)$ & $132(57.4)$ & $<0.001$ \\
\hline Age (years) & $76.4 \pm 9.6$ & $64.3 \pm 4.9$ & $80.8 \pm 6.6$ & $<0.001$ \\
\hline Weight (kg) & $61.2 \pm 12.7(\mathrm{~N}=252)$ & $71.2 \pm 11.5(\mathrm{~N}=63)$ & $57.9 \pm 11.3(\mathrm{~N}=189)$ & $<0.00$ I \\
\hline Creatinine clearance (mL/min) & $57.3 \pm 28.0(\mathrm{~N}=250)$ & $87.8 \pm 24.8(\mathrm{~N}=62)$ & $47.2 \pm 20.8(\mathrm{~N}=188)$ & $<0.001$ \\
\hline \multicolumn{5}{|l|}{ Duration of warfarin therapy } \\
\hline$<5$ years & $85(27.2)$ & $22(26.5)$ & $63(27.4)$ & 0.876 \\
\hline$\geq 5$ years & $228(72.8)$ & $61(73.5)$ & $167(72.6)$ & \\
\hline HAS-BLED score & $2.6 \pm 1.2$ & $2.1 \pm 1.2$ & $2.7 \pm 1.1$ & $<0.001$ \\
\hline $\mathrm{CHADS}_{2}$ score & $2.3 \pm 1.2$ & $1.5 \pm 0.8$ & $2.6 \pm I .1$ & $<0.001$ \\
\hline $\mathrm{CHA}_{2} \mathrm{DS}_{2}$-VASc score & $4.1 \pm 1.8$ & $2.7 \pm 1.4$ & $4.6 \pm 1.7$ & $<0.001$ \\
\hline INR at baseline & $2.0 \pm 0.4(\mathrm{~N}=308)$ & $2.0 \pm 0.5(\mathrm{~N}=80)$ & $2.0 \pm 0.4(\mathrm{~N}=228)$ & 1.000 \\
\hline FIR (\%) & $66.0 \pm 28.5(\mathrm{~N}=309)$ & $47.3 \pm 29.6(\mathrm{~N}=8 \mathrm{I})$ & $72.7 \pm 25.0(\mathrm{~N}=228)$ & $<0.001$ \\
\hline Patients achieving therapeutic goals & 209 (67.9) $(\mathrm{N}=308)$ & $39(48.8)(\mathrm{N}=80)$ & $170(74.6)(\mathrm{N}=228)$ & $<0.001$ \\
\hline Number of concomitant drugs & $6.1 \pm 3.3$ & $5.0 \pm 2.8$ & $6.5 \pm 3.3$ & $<0.001$ \\
\hline Frequency of INR measurement (per year) & $9.0 \pm 3.9(\mathrm{~N}=309)$ & $8.2 \pm 3.6(\mathrm{~N}=8 \mathrm{I})$ & $9.2 \pm 3.9(\mathrm{~N}=228)$ & 0.044 \\
\hline Percentage of patients whose warfarin & 41.2 & 36.1 & 43.0 & 0.274 \\
\hline \multicolumn{5}{|l|}{ dosages were changed in the past I year } \\
\hline \multicolumn{5}{|l|}{ Self-pay ratio to whole medical costs } \\
\hline $0 \%$ & $25(8.0)$ & $3(3.6)$ & $22(9.6)$ & $<0.001$ \\
\hline $10 \%$ & $165(52.7)$ & $2(2.4)$ & $163(70.9)$ & \\
\hline $20 \%$ & $19(6.1)$ & $\mathrm{I}(\mathrm{I} .2)$ & $18(7.8)$ & \\
\hline $30 \%$ & $102(32.6)$ & $76(91.6)$ & $26(11.3)$ & \\
\hline Others & $2(0.6)$ & $\mathrm{I}(\mathrm{I} .2)$ & $\mathrm{I}(0.4)$ & \\
\hline
\end{tabular}

Notes: Data are presented as $\mathrm{N}(\%)$ or mean \pm SD. The number of patients used for the analysis was 313,83 , and 230 for total patients, patients aged $<70$ years, and patients aged $\geq 70$ years, respectively, unless otherwise specified. In patients with NVAF, target INR level is within the following range according to Japanese treatment guidelines (Guidelines for Pharmacotherapy of Atrial Fibrillation [JCS 20I3]): 2.0-3.0 for patients $<70$ years old and I.6-2.6 for patients $\geq 70$ years old. ${ }^{21}$ CHADS, score was calculated based on age $>75$ years and the presence of congestive heart failure, hypertension, diabetes, and 2 points for stroke or transient ischemic attack. $\mathrm{CHA}_{2} \mathrm{DS}_{2}-\mathrm{VASc}$ score was calculated by allotting I point each for congestive heart failure/left ventricular dysfunction, hypertension, diabetes, vascular disease (prior myocardial infarction, peripheral arterial disease, or aortic plaque), age between 65 and 74 years, and female gender; 2 points each were allotted for age $>75$ years and prior stroke, or transient ischemic attack. HAS-BLED score was calculated based on the following components: hypertension, abnormal renal function, abnormal liver function, previous stroke, bleeding history or predisposition, labile INR, age $>65$ years, drugs predisposing patient to bleeding (antiplatelet agents or nonsteroidal anti-inflammatory drugs), and alcohol abuse. ${ }^{2}$ Comparison between patients $<70$ years old and those $\geq 70$ years old. An unpaired $t$-test and a chi-square test were used for continuous variables and categorical variables, respectively.

Abbreviations: FIR, frequency in therapeutic range; INR, international normalized ratio; NVAF, nonvalvular atrial fibrillation.

(55.3\%), as shown in Table 2. However, although these patients had been advised to switch to DOACs, they chose to continue warfarin therapy primarily due to "much higher drug prices of DOACs" (47.2\%) and their "long-term experience

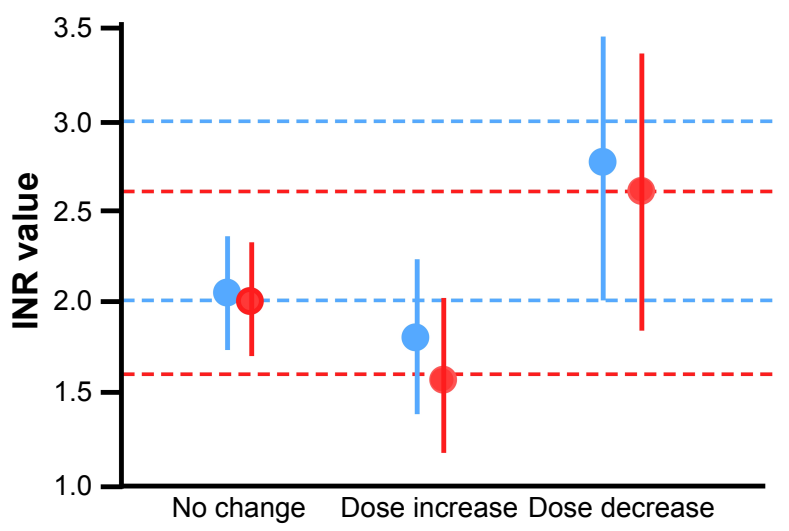

Figure 2 INR values when doses of warfarin were increased or decreased in patients $<70$ years old and $\geq 70$ years old.

Notes: Mean \pm SD is shown. Blue $=$ patients aged $<70$ years; red $=$ patients aged $\geq 70$ years. Dotted lines show the therapeutic ranges recommended by the Japanese treatment guidelines for each age range.

Abbreviation: INR, international normalized ratio.
Table 2 Reasons physicians recommended switching to DOACs $(\mathrm{N}=161)$

\begin{tabular}{ll}
\hline & $\mathbf{n}(\%)$ \\
\hline Medical reasons & \\
Unstable INR & $19(\mathrm{II} .8)$ \\
Interaction with other drugs & $\mathrm{I}(0.6)$ \\
High bleeding risk & $\mathrm{II}(6.8)$ \\
Better safety and efficacy profile of DOACs & $89(55.3)$ \\
Concomitant disease & $0(0)$ \\
Reduction of overall risk accompanied with & $2(1.2)$ \\
warfarin therapy & \\
Bleeding during warfarin therapy & $0(0)$ \\
Timing of dental procedure & $\mathrm{I}(0.6)$ \\
Timing of ablation & $0(0)$ \\
Timing of surgical procedure & $0(0)$ \\
Pregnancy & $0(0)$ \\
Other medical reasons & $\mathrm{I}(0.6)$ \\
Nonmedical reasons & \\
To avoid regular INR measurement & $2 \mathrm{I}(\mathrm{I})$ \\
To avoid food restrictions & $\mathrm{I}(3(8.1)$ \\
Dose adjustment of warfarin is bothersome & $2(1.2)$ \\
To reduce total number of pills & $0(0)$ \\
Other nonmedical reasons & $\mathrm{I}(0.6)$ \\
\hline Not
\end{tabular}

Note: Data are presented as $n(\%)$.

Abbreviations: DOAC, direct oral anticoagulant; INR, international normalized ratio. 
Table 3 Reasons in favor of continued warfarin therapy $(\mathrm{N}=\mid 52)$

\begin{tabular}{ll}
\hline & $\mathbf{n}(\%)$ \\
\hline Medical reasons & \\
INR stably controlled & $57(37.5)$ \\
Decreased renal function & $39(25.7)$ \\
No bleeding or ischemic events while taking warfarin & $8(5.3)$ \\
Concerns about bleeding and embolic events during switch & $2(1.3)$ \\
Frequent dose adjustments required & $3(2.0)$ \\
Other medical reasons & $6(3.9)$ \\
Nonmedical reasons & \\
Higher medical costs of DOACs compared to warfarin & $11(7.2)$ \\
Patients were satisfied with warfarin therapy & $9(5.9)$ \\
Patients had concerns about switching & $13(8.6)$ \\
INR measurement motivates patients to continue therapy & $0(0)$ \\
Other nonmedical reasons & $2(1.3)$ \\
Other reasons & $2(1.3)$ \\
\hline
\end{tabular}

Note: Data are presented as $n(\%)$.

Abbreviations: DOAC, direct oral anticoagulant; INR, international normalized ratio.

with warfarin without any trouble" $(31.7 \%)$. Among the remaining half of the patients who were not advised to switch from warfarin to DOACs, leading reasons for continuing warfarin treatment were "INR stably controlled" (37.5\%) and "decreased renal function" (25.7\%) (Table 3).

\section{Questionnaire results: physicians' insight into anticoagulation therapy}

Tables 4 and 5 show physicians' responses to general questions of patient suitability for warfarin versus DOAC treatment (refer to Figure S1 for the questionnaire). In response to the question "Which patients do you think are suitable for warfarin treatment?", $81.6 \%$ of physicians selected "patients with decreased renal function", and $68.4 \%$ selected "patients

Table 4 Physicians' perspective on patients suitable for warfarin treatment $(\mathrm{N}=38)$

\begin{tabular}{ll}
\hline Characteristics & $\mathbf{n}(\%)$ \\
\hline Decreased renal function & $31(81.6)$ \\
Low body weight & $16(42.1)$ \\
INR within the recommended therapeutic range & $20(52.6)$ \\
No stroke events with INR below the therapeutic range & $4(10.5)$ \\
Patient satisfied with warfarin & $26(68.4)$ \\
Frequent dose adjustments required & $10(26.3)$ \\
Self-pay ratio of medical costs: $0 \%$ & $0(0.0)$ \\
Self-pay ratio of medical costs: $10 \%$ & $0(0.0)$ \\
Self-pay ratio of medical costs: $20 \%$ & $1(2.6)$ \\
Self-pay ratio of medical costs: $30 \%$ & $16(42.1)$ \\
NVAF patients with coronary artery disease & $0(0.0)$ \\
NVAF patients with mitral valve stenosis & $22(57.9)$ \\
NVAF patients with valvular disease & $7(18.4)$ \\
Other & $3(7.9)$ \\
\hline Note: Data
\end{tabular}

Note: Data are presented as $n(\%)$.

Abbreviations: INR, international normalized ratio; NVAF, nonvalvular atrial fibrillation.
Table 5 Physicians' perspective on patients suitable for switching to DOACs $(\mathrm{N}=38)$

\begin{tabular}{ll}
\hline Characteristics & $\mathbf{n}(\%)$ \\
\hline All patients for whom DOACs are indicated are suitable & $9(23.7)$ \\
INR consistently outside the therapeutic range & $29(76.3)$ \\
Fluctuations in INR & $34(89.5)$ \\
Inadequate dietary restriction & $31(81.6)$ \\
Dehydration & $4(10.5)$ \\
Patients aged $<65$ years & $8(21.1)$ \\
Patients aged $\geq 65$ and $<75$ years & $10(26.3)$ \\
Patients aged $\geq 75$ years & $8(21.1)$ \\
Diabetes mellitus & $4(10.5)$ \\
Concomitant treatment with NSAIDs & $8(21.1)$ \\
Concomitant treatment with antiplatelet drug & $12(31.6)$ \\
Patients requiring surgery & $18(47.4)$ \\
Patients scheduled for ablation treatment & $16(42.1)$ \\
Patients scheduled for dental procedure & $6(15.8)$ \\
Dementia & $10(26.3)$ \\
Depression & $1(2.6)$ \\
Self-pay ratio of medical costs: $0 \%$ & $11(28.9)$ \\
Self-pay ratio of medical costs: I0\% & $12(31.6)$ \\
Self-pay ratio of medical costs: $20 \%$ & $4(10.5)$ \\
Self-pay ratio of medical costs: $30 \%$ & $2(5.3)$ \\
Other & $0(0.0)$ \\
\hline
\end{tabular}

Note: Data are presented as $\mathrm{n}(\%)$.

Abbreviations: DOAC, direct oral anticoagulant; INR, international normalized ratio; NSAID, nonsteroidal anti-inflammatory drug.

who are satisfied with warfarin". A large majority of physicians responded that switching to DOACs is appropriate for patients with fluctuating INR levels (89.5\%) and for patients with INR values consistently outside of the therapeutic range $(76.3 \%)$.

\section{A comparison of patients on warfarin therapy (current study) versus patients who switched to apixaban (AGAIN study)}

Table 6 shows the demographic and clinical characteristics of patients continuously treated with warfarin and those who switched from warfarin to a DOAC. There were significant differences between the two groups in the self-pay ratio of medical costs $(P<0.0001)$, duration of warfarin treatment $(P<0.0001)$, and the percentage of patients aged $\geq 70$ years whose baseline INR values were within the therapeutic range $(P<0.0001)$.

\section{Discussion}

This study surveyed patient characteristics, INR values, and physicians' and patients' reasons for continuing warfarin therapy rather than switching to DOACs in a population of patients with NVAF treated with warfarin. We found that $\sim 50 \%$ of patients on warfarin were never counseled by 
Table 6 Demographic and clinical characteristics of patients receiving continued warfarin therapy (current study) and patients who switched to apixaban (AGAIN study ${ }^{38}$ )

\begin{tabular}{|c|c|c|c|}
\hline & SELECT $(\mathbf{N}=3 \mid 3)$ & AGAIN (N=697) & $P$-value \\
\hline Male gender & 197 (62.9) & $433(62.1)$ & 0.8045 \\
\hline Age (years) & $76.4 \pm 9.6$ & $76.2 \pm 9.1$ & 0.6816 \\
\hline Weight (kg) & $61.2 \pm 12.7(\mathrm{~N}=252)$ & $60.6 \pm 12.6(\mathrm{~N}=572)$ & 0.5245 \\
\hline Creatinine clearance $(\mathrm{mL} / \mathrm{min})$ & $57.3 \pm 28.0(\mathrm{~N}=250)$ & $60.8 \pm 43.0(\mathrm{~N}=33 \mathrm{I})$ & 0.2551 \\
\hline HAS-BLED score & $2.6 \pm 1.2$ & $2.6 \pm I .1$ & 1.000 \\
\hline $\mathrm{CHADS}_{2}$ score & $2.3 \pm 1.2$ & $2.5 \pm 1.3$ & 0.1171 \\
\hline $\mathrm{CHA}_{2} \mathrm{DS}_{2}$-VASc score & $4.1 \pm 1.8$ & $4.0 \pm 1.7$ & 0.2877 \\
\hline INR at baseline & $2.0 \pm 0.4(\mathrm{~N}=308)$ & $2.0 \pm 0.6(\mathrm{~N}=672)$ & 0.4718 \\
\hline FIR (\%) & $66.0 \pm 28.5(\mathrm{~N}=309)$ & $60.2 \pm 30.4(\mathrm{~N}=672)$ & 0.004 \\
\hline \multicolumn{4}{|c|}{ Patients achieving therapeutic goals } \\
\hline$<70$ years & $39(48.8)(\mathrm{N}=80)$ & $55(38.7)(\mathrm{N}=142)$ & 0.1477 \\
\hline$\geq 70$ years & $170(74.6)(\mathrm{N}=228)$ & $304(57.4)(\mathrm{N}=530)$ & $<0.0001$ \\
\hline \multicolumn{4}{|l|}{ Duration of warfarin therapy } \\
\hline$<5$ years & $85(27.2)$ & $261(37.4)$ & $<0.0001$ \\
\hline$\geq 5$ years & $228(72.8)$ & $326(46.8)$ & \\
\hline \multicolumn{4}{|l|}{ Self-pay ratio of total medical costs } \\
\hline $0 \%$ & $25(8.0)$ & $104(14.9)$ & $<0.000$ I \\
\hline $10 \%$ & I 65 (52.7) & $4 I I(59.0)$ & \\
\hline $20 \%$ & $19(6.1)$ & $42(6.0)$ & \\
\hline $30 \%$ & $102(32.6)$ & $139(19.9)$ & \\
\hline Other & $2(0.6)$ & I (0.I) & \\
\hline
\end{tabular}

Notes: Data are presented as $N(\%)$ or mean \pm SD. The number of the patients used for the analysis was 313 for the SELECT study (current study) and 697 for the AGAIN study, unless otherwise specified. In patients with NVAF, INR levels should be maintained within the following ranges according to Japanese treatment guidelines (Guidelines for Pharmacotherapy of Atrial Fibrillation [JCS 20I3]): 2.0-3.0 for patients $<70$ years old and I.6-2.6 for patients $\geq 70$ years old. ${ }^{21} \mathrm{CHADS}_{2}$ score was calculated based on age $>75$ years and the presence of congestive heart failure, hypertension, diabetes, and 2 points for stroke or transient ischemic attack. $\mathrm{CHA}_{2} \mathrm{DS} \mathrm{S}_{2}-\mathrm{VASc}$ score was calculated by allotting I point each for congestive heart failure/left ventricular dysfunction, hypertension, diabetes, vascular disease (prior myocardial infarction, peripheral arterial disease, or aortic plaque), age between 65 and 74 years, and female gender; 2 points each were allotted for age $>75$ years and prior stroke, transient ischemic attack, or thromboembolism. HAS-BLED score was calculated based on the following components: hypertension, abnormal renal function, abnormal liver function, previous stroke, bleeding history or predisposition, labile INR, age $>65$, drugs predisposing to bleeding (antiplatelet agents or nonsteroidal anti-inflammatory drugs), and alcohol abuse. Abbreviations: FIR, frequency in therapeutic range; INR, international normalized ratio; NVAF, nonvalvular atrial fibrillation.

their physician about DOACs as an alternative treatment option, and therefore continued warfarin therapy primarily as a result of physicians' medical judgment. Additionally, we found that the percentage of patients with therapeutic INR values was notably high among patients aged $\geq 70$ years.

In our investigation into the reasons for continuing warfarin rather than switching to DOACs, we found that about half of the patients remaining on warfarin therapy had never been advised by their physicians to switch therapies, nor had they been informed about DOACs as a potential alternative to warfarin. Medical rationales for continuing warfarin outweighed reasons related to patient convenience, including "INR stably controlled by warfarin", as reported by $37.5 \%$ of physicians (Table 3). When asked in general terms about which patients are suitable for continuing warfarin treatment, $52.6 \%$ of physicians responded, "patients whose INR is controlled within the recommended therapeutic range" (Table 4). In contrast, $76.3 \%$ of physicians stated that patients should be switched to DOACs "when INR values are not consistently within the therapeutic range of warfarin recommended by the guidelines". Correspondingly, $89.5 \%$ of physicians replied that "patients with fluctuations in INR" are appropriate for DOACs (Table 5).

Physicians reported that patients with large visit-to-visit INR fluctuations may carry a higher risk of bleeding and ischemic stroke. However, the opposite may not always be true, as patients receive the maximum benefit of stable INR only when INR is maintained within the optimal therapeutic range. Furthermore, results from previous randomized controlled trials suggest that patients treated with DOACs may experience fewer bleeding and/or ischemic events compared to patients on warfarin with INR levels stably maintained inside the therapeutic range. Hemorrhage has also been observed in patients with INR $<3.0$ in real-world settings. ${ }^{22,23}$ Therefore, stably controlled INR may not always be a logical reason to forgo transitioning to DOACs, although many physicians reportedly believe that control status of INR is the most critical factor for deciding to continue warfarin therapy.

The second most common reason for not recommending DOACs was "reduced renal function", reported by $25.7 \%$ 
of physicians (Table 3). Warfarin is metabolized in the liver, whereas all DOACs have some degree of renal excretion; dabigatran is the highest at $80 \%$, followed by edoxaban $(50 \%)$, rivaroxaban $(33 \%)$, and apixaban $(27 \%){ }^{24-28}$ Therefore, warfarin can be expected to provide more stable anticoagulation than DOACs in patients with reduced renal function. However, patients with impaired renal function were excluded from the large-scale randomized Phase III trials that investigated the efficacy and safety of DOACs in comparison to warfarin. ${ }^{11-13,29}$ In one study comparing apixaban and warfarin, apixaban reduced the rate of stroke, death, and major bleeding, regardless of renal function. ${ }^{30}$ Further studies are needed to evaluate the efficacy and safety of DOACs compared with warfarin in patients with impaired renal function.

As previously mentioned, $51.4 \%$ of patients taking warfarin had been advised by their physician to switch to a DOAC. Although it is not entirely clear why warfarin therapy was continued in these patients, patient preference likely affected this decision. Our results revealed that patients elected to continue warfarin therapy primarily due to the "much higher drug prices of DOACs" (reported by $47.2 \%$ of patients) and a "long-term experience of warfarin without any trouble" (31.7\%). AF commonly occurs in the elderly, as reflected in this survey population $(73.5 \%$ of patients were $\geq 70$ years old). Consequently, many patients with AF have a limited income - often solely pension - and may not be able to afford more expensive medications. This may explain why drug price was the leading reason for continuing warfarin, the least expensive OAC.

As shown in Table 6, there were minimal differences in clinical and demographic background between patients on warfarin (from the current study) and patients who switched to apixaban (from the AGAIN study). Only three significant differences in background were observed between the two groups: 1) duration of warfarin treatment, 2) percentage of patients aged $\geq 70$ years with therapeutic INR levels, and 3) self-pay ratio of medical costs. Not coincidentally, these differences between warfarin users and apixaban users correspond with the reasons that patients reported a preference for continuing warfarin therapy, namely, that patients on long-term warfarin have had positive experiences, that patients have been able to maintain stable INR with warfarin, and that patients with higher self-pay ratios tend to choose the more affordable OAC.

The aim of this study was to explore the reasons for continued warfarin use from the perspective of both physicians and patients. However, the most critical element in this scenario, regardless of the type of OAC, is patient compliance with medications as prescribed by physicians. Patient satisfaction with and preference for a given pharmaceutical regimen may have a significant impact on medication adherence. ${ }^{31}$ The importance of patient adherence to anticoagulant therapy for prevention of stroke cannot be overstated; a single missed dose may lead to stroke. ${ }^{32,33}$ Therefore, patient preference for anticoagulation therapy should be taken into consideration to maintain optimal medication adherence. Equally important is a healthy doctor-patient relationship that includes discussion of all treatment options and frequent communication about patient satisfaction with anticoagulation therapy.

As shown in Table 1, mean INR values were comparable between patients aged $<70$ years and $\geq 70$ years, indicating that physicians are not always strictly adherent to the Japanese Circulation Society's 2013 Guidelines for Pharmacotherapy of Atrial Fibrillation; these guidelines recommend that INR levels in patients with NVAF should be maintained between 2.0 and 3.0 in patients aged $<70$ years old, and between 1.6 and 2.6 in patients aged $\geq 70$ years old. ${ }^{21}$ As shown in Figure 2, physicians may be targeting the INR range of 1.6-2.6 even in younger patients, despite Japanese guideline recommendations for a therapeutic range of 2.0-3.0. Similar results have been reported by investigators from the Fushimi Registry, a communitybased survey of patients with AF in Japan that primarily consists of private clinics of general practitioners, ${ }^{34,35}$ and the J-RHYTHM Registry, a nationwide registry of patients with AF recruited from hospitals and clinics specializing in cardiology. ${ }^{36,37}$ This finding implies that physicians may treat patients of all ages with relatively low doses of warfarin to maintain INR values between 1.6 and 2.6 regardless of guideline recommendations, likely out of concern related to the development of bleeding events. Taken together, these results suggest that INR is suboptimally controlled in patients aged $<70$ years, regardless of the specialty of the physician managing care.

\section{Limitations}

This study has several limitations because of its design and methodology. The study was conducted at a limited number of institutions that were chosen at random from the AGAIN study; therefore, the results may not be suitable for extrapolation to general practice in Japan or other countries. Additionally, the questionnaires used in this study have not been validated linguistically and psychometrically, and methods for using them have not been standardized. 


\section{Conclusion}

Approximately half of the patients in this study received a recommendation from their physician to switch from warfarin to a DOAC, primarily on the basis of improved efficacy and safety, but elected not to change regimens because of the high price of DOACs. In the remaining half of the study population, physician preference or specific patient characteristics prevented a change of therapy. From the physician's perspective, stable INR control was the most important reason to continue warfarin, even if INR values were below the therapeutic range. For patients, lower cost and long-term positive experiences with warfarin constituted the rationale for warfarin preference. Ultimately, a healthy doctor-patient relationship that includes discussion of all treatment options and frequent communication about patient satisfaction with anticoagulation therapy is crucial for achieving medication adherence.

\section{Acknowledgments}

The authors would like to thank the doctors participating in this study. We would like to acknowledge the contribution of Mebix, Inc. to this study, including site selection, site monitoring, study management, data management, and statistical analysis. We thank Ms Pearl Gomes from Cactus Communications KK for editing the manuscript. The study and editing of the manuscript were supported by BristolMyers Squibb KK and Pfizer Japan Inc.

\section{Author contributions}

All authors contributed toward study design, data analysis, drafting and revising the paper and agree to be accountable for all aspects of the work.

\section{Disclosure}

TI received research grants from Bristol-Myers Squibb KK, Daiichi Sankyo KK, Nippon Boehringer Ingelheim, honoraria and consulting fees (for speaker, writer and/or adviser) from Bayer Yakuhin Ltd., Bristol-Myers Squibb KK, Daiichi Sankyo KK, Nippon Boehringer Ingelheim, and Pfizer Japan Inc. MY received a research grant from Nippon Boehringer Ingelheim, honoraria and consulting fees from Bayer Yakuhin Ltd., Bristol-Myers Squibb KK, Daiichi Sankyo KK, Nippon Boehringer Ingelheim, and Pfizer Japan Inc. MK is an employee of Bristol-Myers Squibb KK. MI is an employee of Pfizer Japan Inc. The authors report no other conflicts of interest in this work.

\section{References}

1. Hata J, Tanizaki Y, Kiyohara Y, et al. Ten year recurrence after first ever stroke in a Japanese community: the Hisayama study. $J$ Neurol Neurosurg Psychiatry. 2005;76(3):368-372.
2. Perera KS, Vanassche T, Bosch J, et al; ESUS Global Registry Investigators. Global survey of the frequency of atrial fibrillation-associated stroke: embolic stroke of undetermined source global registry. Stroke. 2016; 47(9):2197-2202.

3. Prystowsky EN, Benson DW Jr, Fuster V, et al. Management of patients with atrial fibrillation. A statement for healthcare professionals. From the subcommittee on electrocardiography and electrophysiology, American Heart Association. Circulation. 1996;93(6):1262-1277.

4. Wolf PA, Abbott RD, Kannel WB. Atrial fibrillation: a major contributor to stroke in the elderly. The Framingham Study. Arch Intern Med. 1987;147(9):1561-1564.

5. Benjamin EJ, Levy D, Vaziri SM, D'Agostino RB, Belanger AJ, WolfPA. Independent risk factors for atrial fibrillation in a population-based cohort. The Framingham Heart Study. JAMA. 1994;271(11):840-844.

6. Kokubo Y, Watanabe M, Higashiyama A, Nakao YM, Kusano K, Miyamoto Y. Development of a basic risk score for incident atrial fibrillation in a Japanese general population-the Suita Study. Circ J.2017;81(11): $1580-1588$.

7. Wang TJ, Parise H, Levy D, et al. Obesity and the risk of new-onset atrial fibrillation. JAMA. 2004;292(20):2471-2477.

8. January CT, Wann LS, Alpert JS, et al. 2014 AHA/ACC/HRS guideline for the management of patients with atrial fibrillation: a report of the American College of Cardiology/American Heart Association Task Force on Practice Guidelines and the Heart Rhythm Society. J Am Coll Cardiol. 2014;64(21):e1-e76.

9. Kirchhof P, Benussi S, Kotecha D, et al. 2016 ESC Guidelines for the management of atrial fibrillation developed in collaboration with EACTS. Europace. 2016;18(11):1609-1678.

10. Mozos I, Stoian D, Luca CT. Crosstalk between vitamins A, B12, D, K, C, and E status and arterial stiffness. Dis Markers. 2017;2017:8784971.

11. Granger CB, Alexander JH, McMurray JJ, et al. Apixaban versus warfarin in patients with atrial fibrillation. $N$ Engl J Med. 2011;365(11): 981-992.

12. Patel MR, Mahaffey KW, Garg J, et al. Rivaroxaban versus warfarin in nonvalvular atrial fibrillation. $N$ Engl J Med. 2011;365(10):883-891.

13. Connolly SJ, Ezekowitz MD, Yusuf S, et al. Dabigatran versus warfarin in patients with atrial fibrillation. $N$ Engl J Med. 2009;361(12): $1139-1151$.

14. Larsen TB, Rasmussen LH, Skjøth F, et al. Efficacy and safety of dabigatran etexilate and warfarin in "real-world" patients with atrial fibrillation: a prospective nationwide cohort study. J Am Coll Cardiol. 2013; 61(22):2264-2273.

15. Laliberte F, Cloutier M, Nelson WW, et al. Real-world comparative effectiveness and safety of rivaroxaban and warfarin in nonvalvular atrial fibrillation patients. Curr Med Res Opin. 2014;30(7):1317-1325.

16. Hernandez I, Baik SH, Pinera A, Zhang Y. Risk of bleeding with dabigatran in atrial fibrillation. JAMA Intern Med. 2015;175(1):18-24.

17. Lauffenburger JC, Farley JF, Gehi AK, Rhoney DH, Brookhart MA, Fang G. Effectiveness and safety of dabigatran and warfarin in realworld US patients with non-valvular atrial fibrillation: a retrospective cohort study. J Am Heart Assoc. 2015;4(4):e001798.

18. Bouillon K, Bertrand M, Maura G, Blotiere PO, Ricordeau P, Zureik M. Risk of bleeding and arterial thromboembolism in patients with nonvalvular atrial fibrillation either maintained on a vitamin $\mathrm{K}$ antagonist or switched to a non-vitamin K-antagonist oral anticoagulant: a retrospective, matched-cohort study. Lancet Haematol. 2015;2(4): e150-e159.

19. Lip GY, Keshishian A, Kamble S, et al. Real-world comparison of major bleeding risk among non-valvular atrial fibrillation patients initiated on apixaban, dabigatran, rivaroxaban, or warfarin. A propensity score matched analysis. Thromb Haemost. 2016;116(5): 975-986.

20. Lip GY, Pan X, Kamble S, et al. Major bleeding risk among non-valvular atrial fibrillation patients initiated on apixaban, dabigatran, rivaroxaban or warfarin: a "real-world" observational study in the United States. Int J Clin Pract. 2016;70(9):752-763.

21. JCS Joint Working Group. Guidelines for Pharmacotherapy of Atrial Fibrillation (JCS 2013). Circ J. 2014;78(8):1997-2021. 
22. Yamaguchi T. Optimal intensity of warfarin therapy for secondary prevention of stroke in patients with nonvalvular atrial fibrillation: a multicenter, prospective, randomized trial. Japanese Nonvalvular Atrial Fibrillation-Embolism Secondary Prevention Cooperative Study Group. Stroke. 2000;31(4):817-821.

23. Yasaka M, Minematsu K, Yamaguchi T. Optimal intensity of international normalized ratio in warfarin therapy for secondary prevention of stroke in patients with non-valvular atrial fibrillation. Intern Med. 2001;40(12):1183-1188.

24. Blech S, Ebner T, Ludwig-Schwellinger E, Stangier J, Roth W. The metabolism and disposition of the oral direct thrombin inhibitor, dabigatran, in humans. Drug Metab Dispos. 2008;36(2):386-399.

25. Stangier J, Rathgen K, Stähle H, Mazur D. Influence of renal impairment on the pharmacokinetics and pharmacodynamics of oral dabigatran etexilate: an open-label, parallel-group, single-centre study. Clin Pharmacokinet. 2010;49(4):259-268.

26. Parasrampuria DA, Truitt KE. Pharmacokinetics and pharmacodynamics of edoxaban, a non-vitamin $\mathrm{K}$ antagonist oral anticoagulant that inhibits clotting factor Xa. Clin Pharmacokinet. 2016;55(6): $641-655$.

27. Weinz C, Schwarz T, Kubitza D, Mueck W, Lang D. Metabolism and excretion of rivaroxaban, an oral, direct factor $\mathrm{Xa}$ inhibitor, in rats, dogs, and humans. Drug Metab Dispos. 2009;37(5):1056-1064.

28. Frost C, Wang J, Nepal S, et al. Apixaban, an oral, direct factor Xa inhibitor: single dose safety, pharmacokinetics, pharmacodynamics and food effect in healthy subjects. Br J Clin Pharmacol. 2013;75(2):476-487.

29. Giugliano RP, Ruff CT, Braunwald E, et al. Edoxaban versus warfarin in patients with atrial fibrillation. $N$ Engl J Med. 2013;369(22): 2093-2104.

30. Hohnloser SH, Hijazi Z, Thomas L, et al. Efficacy of apixaban when compared with warfarin in relation to renal function in patients with atrial fibrillation: insights from the ARISTOTLE trial. Eur Heart J. 2012; 33(22):2821-2830.
31. Osterberg L, Blaschke T. Adherence to medication. $N$ Engl J Med. 2005;353(5):487-497.

32. Wang Y, Kong MC, Lee LH, Ng HJ, Ko Y. Knowledge, satisfaction, and concerns regarding warfarin therapy and their association with warfarin adherence and anticoagulant control. Thromb Res. 2014;133(4): $550-554$.

33. Shore S, Carey EP, Turakhia MP, et al. Adherence to dabigatran therapy and longitudinal patient outcomes: insights from the veterans health administration. Am Heart J. 2014;167(6):810-817.

34. Akao M, Chun YH, Esato M, et al; Fushimi AF Registry Investigators. Inappropriate use of oral anticoagulants for patients with atrial fibrillation. Circ J. 2014;78(9):2166-2172.

35. Akao M, Chun YH, Wada H, et al; Fushimi AF Registry Investigators. Current status of clinical background of patients with atrial fibrillation in a community-based survey: the Fushimi AF Registry. J Cardiol. 2013; 61(4):260-266.

36. Atarashi H, Inoue H, Okumura K, Yamashita T, Kumagai N, Origasa H; J-RHYTHM Registry Investigators. Present status of anticoagulation treatment in Japanse patients with atrial fibrillation: a report from J-RHYTHM Registry. Circ J. 2011;75(6):1328-1333.

37. Atarashi H, Inoue H, Okumura K, Yamashita T, Origasa H; J-RHYTHM Registry Investigators. Investigation of optimal anticoagulation strategy for stroke prevention in Japanse patients with atrial fibrillation - the J-RHYTHM Registry study design. J Cardiol. 2011;57(1):95-99.

38. Koretsune Y, Ikeda T, Kozuma K, et al. Patient satisfaction after switching from warfarin to apixaban in patients with nonvalvular atrial fibrillation: AGAIN study. Patient Prefer Adherence. 2017;11:1987-1996.
Patient Preference and Adherence

\section{Publish your work in this journal}

Patient Preference and Adherence is an international, peer-reviewed, open access journal that focuses on the growing importance of patient preference and adherence throughout the therapeutic continuum. Patient satisfaction, acceptability, quality of life, compliance, persistence and their role in developing new therapeutic modalities and compounds to optimize

\section{Dovepress}

clinical outcomes for existing disease states are major areas of interest for the journal. This journal has been accepted for indexing on PubMed Central. The manuscript management system is completely online and includes a very quick and fair peer-review system, which is all easy to use. Visit http://www. dovepress.com/testimonials.php to read real quotes from published authors. 